\title{
The effect of hemoadsorption on rivaroxaban blood plasma concentration in emergency cardiac surgery
}

\author{
Bernard Krüger ${ }^{1,2}$ (D) Tobias Renner $^{1} \cdot$ Mathias Van Hemelrijck $^{3} \cdot$ Juri Sromicki $^{3} \cdot$ Ahmed Ouda $^{3}$. \\ Carlos - A. Mestres $^{3}$ (i)
}

Received: 31 December 2020 / Revised: 12 March 2021 / Accepted: 18 March 2021 / Published online: 23 April 2021

(C) The Author(s) 2021

\begin{abstract}
Hemoadsorption was used in a 59-year-old patient with an acute type A aortic dissection, who was on rivaroxaban and dual antiplatelet therapy with clopidogrel and acetylsalicylic acid. Our aim was to expeditiously remove rivaroxaban preoperatively. After $8 \mathrm{~h}$ of hemoadsorption, the rivaroxaban blood plasma concentration (RBPC) did not decrease below $42.1 \mu \mathrm{g} / \mathrm{l}$. Intraoperatively, hemoadsorption was repeated during extracorporeal circulation. Sixteen hours after surgery and a total of $13 \mathrm{~h}$ of hemoadsorption, the RBPC was $40.1 \mu \mathrm{g} / \mathrm{l}$. Thereafter, the RBPC spontaneously decreased to $24.7 \mu \mathrm{g} / \mathrm{l}$ within $14 \mathrm{~h}$. In our patient, hemoadsorption may have enhanced rivaroxaban removal at higher RBPC (cutoff value 40-50 $\mu \mathrm{g} / \mathrm{l}$ ). At lower $\mathrm{RBPC}$, the removal of rivaroxaban may depend solely on the natural drug elimination process. The evolution of the RBPC under hemoadsorption in vivo warrants a thorough investigation. Further clinical studies are required to assess the effectiveness and limitations of hemoadsorption to preclude a fatal bleeding event in patients with rivaroxaban in need of major emergency surgery.
\end{abstract}

Keywords Hemoadsorption $\cdot$ Emergency cardiac surgery $\cdot$ Type A aortic dissection $\cdot$ Rivaroxaban $\cdot$ DOAC

\section{Introduction}

Direct oral anticoagulants (DOAC) and antiplatelet drugs may contribute to major bleeding in patients requiring emergency cardiac surgery [1]. For rivaroxaban and dabigatran, in urgent operations, it has been proposed to postpone surgery and monitor the drug concentration until a value of less or equal to $30 \mathrm{ng} / \mathrm{ml}$ is reached to reduce the hemorrhagic risk [2]. However, a more rapid approach in emergency surgery is required to save a patient's life. Strategies to restore the hemostasis system include the removal of the active drug component [3]. Hemoadsorption - a technique similar to hemoperfusionmay be used for this approach. Blood is directed along polymer beads through a cartridge where hydrophobic molecules, up to

Bernard Krüger

Bernard.Krueger@usz.ch

1 Institute of Anesthesiology, University Hospital Zurich, Zurich, Switzerland

2 Intensive Care Unit for Cardiovascular Surgery, University Hospital Zurich, Rämistrasse 100, CH-8091 Zurich, Switzerland

3 Department of Cardiac Surgery, University Hospital Zurich, Zurich, Switzerland a size of $55 \mathrm{kDa}$, are removed [4]. In vitro, hemoadsorption effectively reduced the plasma concentration of two DOACs and ticagrelor [5-7]. In vivo, hemoadsorption has been associated with reduced bleeding and transfusion requirements in surgical patients under rivaroxaban and ticagrelor [1]. However, the evolution of the rivaroxaban blood plasma concentration (RBPC) under hemoadsorption in vivo has not been thoroughly investigated yet.

We present a patient with an acute type A aortic dissection who was on rivaroxaban and dual antiplatelet therapy with clopidogrel and acetylsalicylic acid (ASA). Hemoadsorption was used to enhance the elimination of rivaroxaban and reduce the risk of a postoperative fatal bleeding event. Our aim is to report the course of RBPC under hemoadsorption in a relevant clinical scenario.

\section{Case report}

A 59-year-old male patient, with a history of coronary artery disease, on $75 \mathrm{mg} /$ day clopidogrel, and relapsing deep vein thrombosis, on $20 \mathrm{mg}$ /day rivaroxaban, suddenly experienced chest pain and dyspnea. His left leg was concomitantly swollen and painful. After the onset of symptoms, he self-administered an 
additional dose of $20 \mathrm{mg}$ rivaroxaban and called the emergency service. The patient received $500 \mathrm{mg}$ ASA for potential acute coronary syndrome and was transported to the district hospital. The clinical examination revealed an edematous left lower extremity with no palpable femoral artery pulse, loss of sensibility, and reduced motor function. Computed tomography (CT) demonstrated an acute Stanford type A, DeBakey type I, aortic dissection with malperfusion of the inferior segment of the left kidney, and occlusion of the left common iliac artery (Penn class b). The patient was referred to our hospital for emergency surgery $7 \mathrm{~h}$ after the onset of symptoms. At hospital admission, neurologic symptoms were absent and vital signs were normal. Transthoracic echocardiography disclosed moderate aortic valve regurgitation and no pericardial effusion. Laboratory signs of acute organ dysfunction were absent (lactate $1.8 \mathrm{mmol} / \mathrm{l}$, alanine transaminase $17 \mathrm{U} / \mathrm{l}$, creatine kinase $188 \mathrm{U} / \mathrm{l}$, creatinine $76 \mu \mathrm{mol} /$ 1). While the values of the activated partial thromboplastin time (aPTT) and prothrombin time (PT) were in the normal range with $31 \mathrm{~s}$ and $12.8 \mathrm{~s}$, respectively, the international normalized ratio (INR) of the prothrombin time was mildly elevated with a value of 1.3. In contrast, a chromogenic anti-FXa assay calibrated for rivaroxaban (Biophen DiXal® test kit, Endotell AG, Allschwil, Switzerland) showed an RBPC value of $147.9 \mu \mathrm{g} / \mathrm{l}$. To prevent aortic rupture and treat organ malperfusion, emergency central aortic repair was clearly indicated. However, it was felt that aortic repair, after the administration of $20 \mathrm{mg}$ rivaroxaban $7 \mathrm{~h}$ ago, would entail an unacceptable risk of uncontrollable bleeding and eventual death. Because the patient was hemodynamically stable, it was decided to postpone surgery and treat symptomatic malperfusion of the left leg through an interventional approach. After pelvic angiogram, left femoral direct angiography, and invasive manometry, a membrane fenestration of the left external iliac artery was performed. To completely resolve malperfusion, the left external iliac and common femoral artery received percutaneous transluminal angioplasty (PTA) and stenting. The intervention was successful with no bleeding complications at the vascular access site and no reperfusion syndrome thereafter (maximum lactate value $3.7 \mathrm{mmol} / \mathrm{l}$ ).

The patient was transferred to the intensive care unit (ICU) and connected to a veno-venous hemofilter (multiFiltrate $\mathrm{CiCa}{ }^{\circledR}, \mathrm{Ci}-\mathrm{Ca}{ }^{\circledR}$ Dialysat K2, Fresenius Medical Care, Bad Homburg, Germany; blood flow $150 \mathrm{ml} / \mathrm{min}$, dialysate flow $3000 \mathrm{ml} / \mathrm{h}$ ) equipped with a hemoadsorber (CytoSorb®, CytoSorbents Corporation, Monmouth Junction, NJ, USA; $300 \mathrm{ml}$ ). The purpose of hemoadsorption was to enhance rivaroxaban removal in addition to the natural elimination process. After $2.5 \mathrm{~h}$, the RBPC decreased from $89.4 \mu \mathrm{g} / \mathrm{l}$ at ICU admission to $42.1 \mu \mathrm{g} / \mathrm{l}$. Applying the institutional guidelines of the University Hospital Zurich, with an empirical cutoff RBPC value of $50 \mu \mathrm{g} / \mathrm{l}$, the patient was cleared for surgery. While waiting for an operation theater to become available, the patient remained in the ICU under hemoadsorption. A follow-up measurement showed no further decrease of
RBPC after a total of $8 \mathrm{~h}$ of hemoadsorption. A preoperative rotational thromboelastometry (ROTEM; ROTEM® delta, Tem Innovations $\mathrm{GmbH}$, Munich, Germany) showed a normal result.

Nineteen hours after the onset of symptoms, the patient underwent ascending aorta replacement with open distal anastomosis under hypothermic arrest at $26^{\circ} \mathrm{C}$ core temperature, using right subclavian artery and right atrial cannulation. Cardiopulmonary bypass (CPB; Stöckert S5, LivaNova, UK; CAPIOX® FX25-Oxygenator, Terumo, JPN), aortic crossclamping, and antegrade cerebral perfusion times were 306, 120 , and $71 \mathrm{~min}$, respectively. A second hemoadsorber was used during CPB. The dissection was repaired using Teflon felt and surgical glue; the aorta was replaced by a $30-\mathrm{mm}$ Dacron graft. CPB ultrafiltration was $8500 \mathrm{ml}$ and Cell Saver ${ }^{\circledR}$ blood retransfusion was $1500 \mathrm{ml}$. The chest was left open because of right ventricular dysfunction, a distributive shock, and coagulopathy. Intraoperatively, the minimum thrombocyte count was $30 \mathrm{G} / 1$ and the maximum INR value 2.4, while ROTEM displayed a minimum FIBTEM MCF of $5 \mathrm{~mm}$ and no sign of hyperfibrinolysis in follow-up measurements. Coagulopathy was counteracted by transfusion of three units of fresh frozen plasma and four thrombocyte concentrates, and administration of $1000 \mathrm{IU}$ prothrombin complex concentrate, $6 \mathrm{~g}$ fibrinogen, 500 IU factor VIII combined with 1200 IU von Willebrand factor, $1750 \mathrm{IU}$ factor XIII, and $1500 \mathrm{mg}$ tranexamic acid. Diffuse bleeding subsided $6 \mathrm{~h}$ after surgery. During surgery and the first 24 postoperative hours, a total of seven erythrocyte concentrates were transfused. The cumulative chest tube drainage $24 \mathrm{~h}$ after surgery was $1295 \mathrm{ml}(54 \mathrm{ml} / \mathrm{h}$ average). RBPC follow-up measurements at $16 \mathrm{~h}$ and $30 \mathrm{~h}$ after surgery were $40.1 \mu \mathrm{g} / \mathrm{l}$ and $24.7 \mu \mathrm{g} / \mathrm{l}$, respectively. Postoperatively, renal function deteriorated, but improved after postoperative day (POD) 3, without need for hemodialysis. The sternum was closed on POD 4, but endotracheal extubation was delayed until POD 11 because of the development of a ventilator-associated pneumonia and a mixed hypo- and hyperactive delirium. Electroencephalography and CT scan ruled out nonconvulsive status epilepticus and cerebral insult. On POD 13, the patient was transferred back to the referring institution. The total ICU and hospital length of stay were 26 days and 40 days, respectively. Eighteen months after surgery, our patient is alive and active, without impairing sequelae.

\section{Discussion}

We report a patient who survived major emergency cardiac surgery without fatal bleeding despite preoperative treatment with rivaroxaban and dual antiplatelet therapy. Our strategy to control bleeding was to delay aortic surgery and first treat acute limb malperfusion interventionally, use hemoadsorption preoperatively to expedite rivaroxaban elimination, and counteract the irreversible effects of clopidogrel and ASA on 
platelets intraoperatively by platelet transfusion. As the result of our strategy, and despite a 5-h CPB time with associated consumption coagulopathy, the patient received multiple blood products and coagulation restoring factors; and in the end, it was possible to control bleeding after surgery.

Recently, Hassan et al. reported a lower bleeding and transfusion rate after emergency cardiac surgery in 39 patients on ticagrelor or rivaroxaban with intraoperative hemoadsorption during $\mathrm{CPB}$, of whom only one was treated for acute aortic dissection in the ticagrelor group [1]. In addition, a recent case report described successful urgent off-pump coronary artery bypass surgery in a patient under ticagrelor and rivaroxaban by pre- and intraoperative use of a hemofilter equipped with CytoSorb ${ }^{\circledR}[8]$. In none of these studies, the evolution of RBPC values under hemoadsorption was produced in detail.

Repeated measurements in our patient demonstrated that RBPC value decreased preoperatively from $147.9 \mu \mathrm{g} / \mathrm{l}$ at hospital admission to $89.4 \mu \mathrm{g} / \mathrm{l}$ spontaneously within $4 \mathrm{~h}$ and to $42.1 \mu \mathrm{g} / \mathrm{l}$ during hemoadsorption within $2.5 \mathrm{~h}$. The evolution of the RBPC over time is displayed in Fig. 1. The measured values fall into the area of predicted rivaroxaban blood concentration between the " 5 th percentile" and a "typical patient aged 60 years," described by Mueck et al. in a onecompartment model [9]. However, the course of measured RBPC values in our patient does not completely resemble the curves of the predicted values but shows a steeper course than predicted between 89.4 and $42.1 \mu \mathrm{g} / \mathrm{l}$. This may signify that the elimination of rivaroxaban may have been enhanced by hemoadsorption during this period. The clearance effect of concomitant hemofiltration may be regarded as negligible as rivaroxaban is highly protein-bound in blood plasma and, hence, not considered dialyzable [9].

Continued hemoadsorption up to $13 \mathrm{~h}$ with two sequential adsorbers did not reduce the RBPC below a value of $40.1 \mu \mathrm{g} / \mathrm{l}$ in our patient. Furthermore, the RBPC increased from 42.1 to
$46.1 \mu \mathrm{g} / 1$ during the first hemadsorption period (Fig. 1). In vitro, hemoadsorption removed rivaroxaban up to $91.6 \%$ with a steady plasma concentration $<50 \mu \mathrm{g} / \mathrm{l}$ after $1 \mathrm{~h} \mathrm{[6]}$. Hemoadsorption is considered to remove substances in a concentration-dependent manner [4]. Therefore, at lower RBPC, hemoadsorption may not add to the removal of rivaroxaban and the pharmacokinetics of rivaroxaban may depend solely on the natural drug elimination process in vivo. As approximately $30 \%$ of rivaroxaban is excreted by the kidneys unmetabolized [9], multifactorial perioperative renal dysfunction may explain the delayed RBPC decrease in our patient (Fig. 1).

Knowledge of the unique pharmacokinetic and pharmacodynamic (PK-PD) profile of a drug may represent a keystone for the successful implementation of hemadsorption into clinical practice. In addition to its chemical properties, rivaroxaban was the only coagulation-affecting drug in our patient that was amenable to removal by hemoadsorption, because of a plasma half-life of mean 12.08 (range 4.79-36.43) h and a reversible inhibitory effect on factor Xa [9]. In contrast, the PK-PD profiles of clopidogrel and ASA, with a plasma half-life of $6 \mathrm{~h}$ and $0.322 \mathrm{~h}$ respectively, and an irreversible inhibition of platelet aggregation for a platelet's lifespan $[10,11]$ rendered hemoadsorption ineffective to counteract the action of these drugs. In our opinion, hemoadsorption in clinical practice may be most successful if used early after drug administration in selected drugs with appropriate chemical properties and a suitable PK-PD profile.

\section{Conclusion}

Hemoadsorption may enhance rivaroxaban elimination above a RBPC of 40-50 $\mu \mathrm{g} / 1$. If used preoperatively, hemoadsorption may reduce the time of delay of emergency surgery. Prolonged use of hemoadsorption did not completely purify blood plasma
Fig. 1 Evolution of rivaroxaban and creatinine blood plasma concentration over time. First values were measured at admission to our hospital $-7 \mathrm{~h}$ after the administration of $20 \mathrm{mg}$ rivaroxaban (RXA). \#1 Hemoadsorption period preoperatively during intensive care (ICU). \#2 Hemoadsorption period during surgery $(\mathrm{OR})$

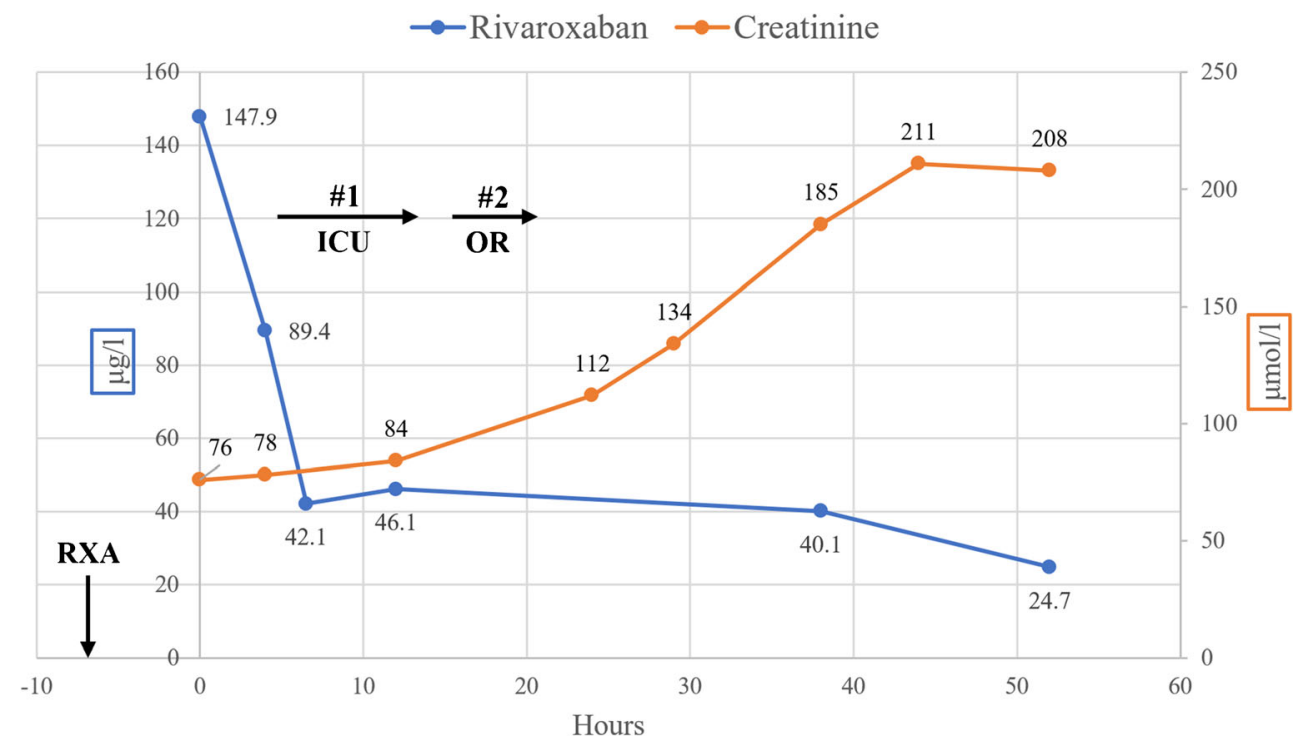


from rivaroxaban in our patient. Further studies are required to establish the appropriate timing and duration of hemoadsorption in patients with rivaroxaban in need of major emergency surgery to assess its effectiveness and limitations in reducing postoperative fatal bleeding.

Funding Open access funding provided by Universität Zürich.

\section{Declarations}

Ethics committee approval Data acquisition and analysis were approved by the ethics council of the Canton of Zurich, Switzerland (BASEC-ID: 2017-00824).

Statement of human and animal rights All procedures performed in human participants were in accordance with the ethical standards of the institutional and/or national research committee and with the 1964 Helsinki Declaration and its later amendments or comparable ethical standards. This article does not contain any studies with animals performed by any of the authors.

Informed consent The patient signed the consent for publication of this report.

Conflict of interest Carlos A. Mestres has received speaker's honoraria from CytoSorbents Corp. The other authors declare no conflict of interest.

Open Access This article is licensed under a Creative Commons Attribution 4.0 International License, which permits use, sharing, adaptation, distribution and reproduction in any medium or format, as long as you give appropriate credit to the original author(s) and the source, provide a link to the Creative Commons licence, and indicate if changes were made. The images or other third party material in this article are included in the article's Creative Commons licence, unless indicated otherwise in a credit line to the material. If material is not included in the article's Creative Commons licence and your intended use is not permitted by statutory regulation or exceeds the permitted use, you will need to obtain permission directly from the copyright holder. To view a copy of this licence, visit http://creativecommons.org/licenses/by/4.0/.

\section{References}

1. Hassan K, Kannmacher J, Wohlmuth P, Budde U, Schmoeckel M, Geidel S. Cytosorb adsorption during emergency cardiac operations in patients at high risk of bleeding. Ann Thorac Surg. 2019;108:4551.

2. Pernod G, Albaladejo P, Godier A, et al. Management of major bleeding complications and emergency surgery in patients on long-term treatment with direct oral anticoagulants, thrombin or factor-Xa inhibitors: proposals of the working group on perioperative haemostasis (GIHP) - March 2013. Arch Cardiovasc Dis. 2013;106:382-93.

3. Moia M, Squizzato A. Reversal agents for oral anticoagulantassociated major or life-threatening bleeding. Intern Emerg Med. 2019;14:1233-9.

4. CytoSorbents manufacturers information. Retrieved March 11, 2021, from http://cytosorb-therapy.com/en/the-adsorber/.

5. Angheloiu AA, Angheloiu GO. Removal of dabigatran using sorbent hemadsorption. Int J Cardiol. 2019;293:73-5.

6. Koertge A, Wasserkort R, Wild T, Mitzner S. Extracorporeal hemoperfusion as a potential therapeutic option for critical accumulation of rivaroxaban. Blood Purif. 2018;45:126-8.

7. Angheloiu GO, Gugiu GB, Ruse C, Pandey R, Dasari RR, Whatling C. Ticagrelor removal from human blood. JACC Basic Transl Sci. 2017;2:135-45.

8. Mair H, Jilek C, Haas B, Lamm P. Ticagrelor and rivaroxaban elimination with cytosorb adsorber before urgent off-pump coronary bypass. Ann Thorac Surg. 2020;110:e369-70.

9. Mueck W, Stampfuss J, Kubitza D, Becka M. Clinical pharmacokinetic and pharmacodynamic profile of rivaroxaban. Clin Pharmacokinet. 2014;53:1-16.

10. Schilling U, Dingemanse J, Ufer M. Pharmacokinetics and pharmacodynamics of approved and investigational P2Y12 receptor antagonists. Clin Pharmacokinet. 2020;59:545-66.

11. Nagelschmitz J, Blunck M, Kraetzschmar J, Ludwig M, Wensing G, Hohlfeld T. Pharmacokinetics and pharmacodynamics of acetylsalicylic acid after intravenous and oral administration to healthy volunteers. Clin Pharmacol. 2014;6:51-9.

Publisher's note Springer Nature remains neutral with regard to jurisdictional claims in published maps and institutional affiliations. 